\title{
FUERO MILITAR: ¿GARANTÍA FUNCIONAL O CONDICIÓN DE IMPUNIDAD?*
}

\section{MILITARY JURISDICTION: FUNCTIONAL WARRANTY OR IMPUNITY CONDITION?}

\author{
Margarita Cárdenas Poveda**
}

Fecha de recepción: 04 de junio del 2013

Fecha de aceptación: 05 de octubre del 2013

\section{Para citar este artículo / To cite this article}

Cárdenas Poveda, Margarita, Fuero militar: ¿garantía funcional o condición de impunidad?, 127 Vniversitas, 61-90 (2013)

doi:10.1144/Javeriana.VJ127.fmgf

* Este resultado de investigación es producto del grupo de investigación Justicia, Ámbito Público y Derechos Humanos, dentro del proyecto aplicación de la jurisprudencia de la Corte Interamericana de Derecho Humanos en los fallos del Consejo de Estado Colombiano, de la Facultad de Derecho y Ciencias Políticas de la Universidad de La Sabana, Chía, Colombia.

** Abogada egresada de la Universidad Militar Nueva Granada. Doctora en Sociología Jurídica de la Universidad Externado de Colombia. Magíster en Derecho Administrativo y Especialista en Instituciones Jurídico-Políticas y Derecho Público y en Derecho Financiero y Bursátil. Jefe del Centro de Investigaciones Socio-Jurídicas y Jefe del Área de Derecho Administrativo y Tributario de la Universidad de La Sabana. Contacto: margarita.cardenas@unisabana.edu.co 


\section{RESUMEN}

La institución jurídica del fuero penal militar ha sido cuestionada constantemente, por considerar que se ha prestado para abusos y ha servido como fuente de impunidad de graves violaciones a los derechos humanos. Ante el desprestigio de la justicia militar, tradicionalmente se contó con un fuero restringido, el cual sufrió una reforma que ha motivado críticas desde todos los sectores, cuya consecuencia fue establecer nuevos órganos en la Jurisdicción Castrense, con funciones que traslapan sus competencias entre sí para definir los conflictos de jurisdicción entre la justicia ordinaria y la Justicia Penal Militar, dejando una estela de dudas en relación con la coherencia con que se da tratamiento a la referida temática.

Por eso la presente investigación busca esclarecer si el fuero penal militar es una garantía funcional, como constitucional y legalmente se encuentra establecido, o si por el contrario en la práctica se ha desnaturalizado por el actuar de la Fuerza Pública y es más bien una condición de impunidad.

Palabras clave autor: Fuero militar, Fuerzas Militares, Justicia Penal Militar, reforma al fuero militar.

Palabras clave descriptor: Teoría legal, derechos civiles, administración de justicia, privilegios e inmunidades. 


\section{ABSTRACT}

The legal institution of military jurisdiction has been constantly questioned by considering that it has been used to abuse and it has worked as a source of impunity in front of serious human rights violations. Before the discredit of Military Justice, the military jurisdiction has been traditionally restricted, but recently it suffered an amendment that has motivated critics from many sectors, reform which established new Military Justice bodies with functions that overlap their powers together to define conflicts of jurisdiction between the ordinary courts and the military justice system, leaving doubts about the consistency by which the aforementioned theme is treated.

Due to these considerations, this research seeks to clarify whether the military criminal jurisdiction is a functional guarantee, as it is constitutionally and legally established, or whether on the contrary, in practice it has been distorted by the actions of the security forces and is rather a condition of impunity.

Keywords author: Military jurisdiction, Military, Military Justice, amendment to military jurisdiction.

Keywords plus: Legal theory, civil and political rights, justice administration, privileges and immunities.

\section{SUMARIO}

INTRODUCCIÓN.- I. EL FUERO MILITAR EN COLOMBIA.- II. LA EXEQUIBILIDAD DE LA JUSTICIA PENAL MILITAR Y SU REFORMA.- III. FUERO MILITAR Y LIBERTADES FUNDAMENTALES.- IV. PERSPECTIVA SOCIOLÓGICA DEL FUERO MILITAR EN COLOMBIA.- CONCLUSIONES. 


\section{INTRODUCCIÓN}

Teniendo como objeto de estudio a las Fuerzas Militares en su relación con el Estado y la sociedad, el presente trabajo es una pesquisa empírica cualitativa de índole social, que en términos generales recurre al método inductivo. Mediante la aplicación de una metodología de recaudo y procesamiento de información primaria, como de los resultados de dicho recaudo y su respectivo análisis, este artículo se presenta como resultado de una investigación empírica y a su vez documental, que se valió de una entrevista de interrogantes abiertos dirigida a personal miembro de las Fuerzas Militares, y como contraste y control ilustrativo, a algunos operadores jurídicos, tanto funcionarios públicos como abogados. Con todo, desde el punto de vista de sus fuentes, no solo trabaja con datos primarios, pues también recurre a la obtención de datos secundarios resultantes de fuentes bibliográficas. Especialmente, la investigación busca establecer la necesidad, oportunidad y conveniencia de la reciente reforma al fuero, con base en la posición jurídica que el Estado ha adoptado de antaño y que hoy encuentra un grave retroceso, de acuerdo con quienes aducen un posible incumplimiento de las obligaciones constitucionales e internacionales adoptadas para dar garantías a las víctimas del conflicto.

\section{EL FUERO MILITAR EN COLOMBIA}

Respecto a la naturaleza jurídica de las Fuerzas Militares en el contexto del ordenamiento legal colombiano, en primer lugar es menester traer a colación su carácter administrativo, dada su vinculación estructural y funcional al sector defensa del Estado, en el marco más amplio de la Rama Ejecutiva del poder público.

En su organización institucional y en orden a garantizar su funcionalidad y fines esenciales, es claro que deben respetarse los principios democráticos de separación de los poderes públicos de suprema dirección y comandancia del Presidente de la República, y de subordinación del poder militar al poder civil. De allí que este diseño institucional posea, como uno de los rasgos principales de la Fuerza Pública, gozar del fuero militar o lo que es igual, que esta no responde ante la justicia penal ordinaria, sino que lo hace 
ante los tribunales militares en situaciones en las que los hechos bajo juicio se relacionan con acciones llevadas a cabo en relación con el servicio.

Si bien los constituyentes de 1991 eran proclives a aceptar la importancia del fuero militar, también fue latente durante los debates, la existencia de una profunda desconfianza respecto al mismo, puesto que existían pruebas fehacientes de que en el pasado había sido una recurrente fuente de impunidad ante graves violaciones a los derechos humanos. El constituyente Vásquez Carrizosa por ejemplo, consideraba el fuero militar como una figura legítima pero desnaturalizada en la práctica con fines inconstitucionales:

[...] las Fuerzas Armadas y de Policía reclaman el fuero militar derivado del artículo 170 de la Constitución (1886) consistente en el privilegio de ser interrogados sus miembros e investigados de manera exclusiva por sus superiores jerárquicos y los jueces militares, con exclusión de los jueces ordinarios, $\underline{\text { lo }}$ que ofrece grandes obstáculos para investigar las violaciones de los Derechos Humanos por parte del personal militar o de policíal.

El constituyente Fabio Villa, por su parte, consideraba que era indispensable ponerle coto al uso excesivo de la figura, limitando los eventos en que la justicia militar pudiese reclamar competencia; en su proyecto de reforma propuso como texto el siguiente:

En definitiva la figura del fuero militar fue insertada en la constitución tal y como ocurre en la normativa constitucional de prácticamente todas las democracias contemporáneas. Sin embargo, y como se verá más adelante, el desprestigio de la justicia militar que existía entre los constituyentes los llevó a permitir solo un fuero de carácter restringido, que en ningún caso, podría usarse como mecanismo de impunidad. La realidad de los últimos 15 años parecería contradecir un poco esta tesis, en la medida que no son demasiadas las decisiones judiciales que los militares pueden mostrar como ejemplos de eficiencia; tampoco son muchos los casos en que la jurisdicción civil ha asumido investigaciones de graves o sistemáticas violaciones a los derechos humanos, desprestigiando aún más la figura del fuero, como se ha podido apreciar recientemente a raíz del Caso Jamundí, donde una unidad del ejército aniquiló a un grupo especial de la policía antinarcóticos y a un informante presuntamente por error, y donde la primera y única decisión judicial al respecto ha sido la declaratoria de incompetencia por parte del juez especializado (de la justicia

1 Alfredo Vásquez Carrizosa, Gaceta Constitucional Número 10. Proyecto de acto Reformatorio de la Constitución Política de Colombia No. 12. Reforma Constitucional sobre los Derechos Humanos, I, 1, Asamblea Nacional Constituyente, Bogotá (1991). 
ordinaria) que conoció el caso y la respectiva remisión a la justicia militar, situación que el mismo presidente Uribe ha repudiado, conocedor de la imagen que tal decisión generó en el país y en la comunidad internacional.

Los orígenes constitucionales del fuero militar datan de la Constitución de la Gran Colombia de 1830, la cual dispuso en su artículo 106: "Los individuos del Ejército y Armada en cuanto al fuero y disciplina, juicios y penas, están sujetos a sus peculiares ordenanzas”. Este antecedente tuvo eco en el texto del otrora artículo 221 de la Constitución Política de 1991, el cual consagraba una justicia y fuero especializados, así: "[d]e los delitos cometidos por los miembros de la Fuerza Pública en servicio activo, y en relación con el mismo servicio, conocerán las Cortes Marciales o Tribunales Militares, con arreglo a las prescripciones del Código Penal Militar. Tales Cortes o Tribunales estarán integrados por miembros de la Fuerza Pública en servicio activo o en retiro".

A partir del artículo 221 ibídem, el artículo 1 del Código Penal Militar reproduce ese texto en su integridad y el artículo 2 establece que son delitos relacionados con el servicio "aquellos cometidos por los miembros de la Fuerza Pública en servicio activo dentro o fuera del territorio nacional, cuando los mismos se deriven directamente de la función militar o policial que la Constitución, la ley y los reglamentos les ha asignado". En aras de precisar el alcance de estas normas, ha dicho la Corte Constitucional en sentencia de 1997:

Un delito está relacionado con el servicio únicamente en la medida en que haya sido cometido en el marco del cumplimiento de la labor "es decir del servicio" que ha sido asignada por la Constitución y la ley a la Fuerza Pública. Esta definición implica las siguientes precisiones acerca del ámbito del fuero penal militar:

- Que para que un delito sea de competencia de la Justicia Penal Militar debe existir un vínculo claro de origen entre él y la actividad del servicio, esto es, el hecho punible debe surgir como una extralimitación o un abuso de poder ocurrido en el marco de una actividad ligada directamente a una función propia del cuerpo armado. Pero aún más, el vínculo entre el delito y la actividad propia del servicio debe ser próximo y directo, y no puramente hipotético y abstracto. Esto significa que el exceso o la extralimitación deben tener lugar durante la realización de una tarea que en sí misma constituya un desarrollo legítimo de los cometidos de las Fuerzas Armadas y la Policía Nacional. Por el contrario, si desde el inicio el agente tiene propósitos criminales, y utiliza 
entonces su investidura para realizar el hecho punible, el caso corresponde a la justicia ordinaria.

- Que el vínculo entre el hecho delictivo y la actividad relacionada con el servicio se rompe cuando el delito adquiere una gravedad inusitada, tal como ocurre con los llamados delitos de lesa humanidad. En estas circunstancias, el caso debe ser atribuido a la justicia ordinaria, dada la total contradicción entre el delito y los cometidos constitucionales de la Fuerza Pública ${ }^{2}$.

\section{Y, de manera consecuente con el planteamiento anterior, agrega:}

El miembro de la Fuerza Pública, así se encuentre en servicio activo, ha podido cometer el crimen al margen de la misión castrense encomendada: en este caso, el solo hecho de estar en servicio activo no lo exime de ser sometido al derecho penal común. Las prerrogativas y la investidura que ostentan los miembros de la Fuerza Pública pierden toda relación con el servicio cuando deliberadamente son utilizadas para cometer delitos comunes, los cuales no dejan de serlo porque el agente se haya aprovechado de las mencionadas prerrogativas e investidura, ya que ellas no equivalen a servicio ni, de otro lado, tienen la virtud de mutar el delito común en un acto relacionado con el mismo. El simple hecho de que una persona esté vinculada a la Fuerza Pública no dota a sus propósitos delictivos de la naturaleza de misión de la Fuerza Pública. Ellos continúan siendo simplemente la voluntad delincuencial imputable a la persona, desconectada del servicio público de la defensa y de la seguridad pública, la cual en un plano de estricta igualdad deberá ser investigada y sancionada según las normas penales ordinarias ${ }^{3}$.

Así, el fuero penal militar se ha definido por la Corte Constitucional como una investidura especial que responde a las diferencias entre los deberes y responsabilidades que tienen los ciudadanos y los que están llamados a asumir los miembros de la Fuerza Pública, "pues a estos últimos la Constitución les asigna una función especial, exclusiva y excluyente: el monopolio del ejercicio coactivo del Estado, que implica el sometimiento a unas reglas especiales propias de la actividad militar". Por ello, la finalidad esencial de este fuero "es que, dentro de los marcos de la Constitución, los miembros de la Fuerza Pública estén cubiertos en sus actividades de servicio por un régimen jurídico penal especial, tanto sustantivo como procedimental, que sea

2 Fundación Ideas para la Paz, Las condiciones de la tortura, I, Siguiendo el conflicto: hechos y análisis de la semana, 1 (2006).

3 Corte Constitucional de Colombia. Sentencia C-358 de 5 de agosto de 1997. M.P.: Carlos Gaviria Díaz.

4 Corte Constitucional de Colombia. Sentencia C-141 de 29 de marzo de 1995. M.P.: Antonio Barrera Carbonell. 
acorde con la especificidad de la organización y funcionamiento de la Fuerza Pública"”.

Pero esta reflexión va más allá, debido a que podría pensarse que más que un régimen especial, el fuero podría convertirse en una prerrogativa que desbordaría los fines de la institución. En este sentido, se ha planteado lo siguiente:

La primera evidencia de la impunidad que reina en Colombia es la distinta aplicación que se hace de las leyes según quien sea el acusado. Si se trata de miembros de la Fuerza Pública o de sus aliados, los paramilitares, los procesos se ralentizan, las pruebas desaparecen, se desacredita o se elimina a los testigos y en muchas ocasiones la víctima acaba huyendo del país para evitar retaliaciones.

Por el contrario, si se sindica a alguien del delito de rebelión la ley se aplica con el máximo rigor hasta el punto de que el acusado tiene que demostrar su inocencia. Además, los procesos iniciados contra uniformados habitualmente son reclamados por la Justicia Penal Militar provocando que el Consejo Superior de la Judicatura tenga que resolver el conflicto de competencias. Este órgano de la justicia reiteradamente argumenta que todos los crímenes de militares y policías, incluidos casos de violaciones carnales, se consideran actos del servicio o con ocasión del servicio y consecuentemente corresponden a la Justicia Penal Militar; la independencia del Consejo se puso en evidencia cuando hace años las Fuerzas Armadas nombraron brigadieres generales a dos de sus magistradas por sus servicios rendidos a las Fuerzas Militares'.

\section{Al respecto, ha comentado la Fundación Ideas para la Paz:}

Tanto la Corte Constitucional como el Consejo Superior de la Judicatura de manera reiterativa han señalado que la competencia de la Justicia Penal Militar es restrictiva y excepcional, y solo debe investigar y conocer de los delitos relacionados con el servicio, entendidos estos como los cometidos por miembros de la Fuerza Pública en servicio activo, cuando los mismos se deriven directamente del ejercicio de la función militar o policial que la Constitución les ha asignado?

Posteriormente, en Sentencia C-533 de 2008, la Corte Constitucional, en ejercicio del control jurisdiccional de las objeciones

5 Corte Constitucional de Colombia. Sentencia C-928 de 7 de noviembre de 2007. M.P.: Humberto Antonio Sierra Porto.

6 L. Pérez Casas, Colombia, la impunidad al orden del día. La Justicia negando la Justicia, I, Jornadas organizadas por Jueces para la Democracia, Ávila -Colectivo de Abogados José Alvear Restrepo, Bogotá (1997).

7 Ministerio de Defensa Nacional, Directiva Permanente $N^{o}$ 19. Reiteración obligaciones para autoridades encargadas de hacer cumplir la ley y evitar homicidios en persona protegida, (I), 
presidenciales al proyecto de ley de nuevo Código Penal Militar, estableció:

$[\ldots]$

9.1. La Justicia Penal Militar nunca puede juzgar los delitos de tortura, genocidio y desaparición forzada, ni ninguno otro de lesa humanidad, o que signifiquen atentado contra el Derecho Internacional Humanitario y las conductas que sean abiertamente contrarias a la función constitucional de la Fuerza Pública y que por su sola comisión rompan el nexo funcional del agente con el servicio. 9.2. El fuero militar cobija única y exclusivamente los delitos cometidos por los miembros de la Fuerza Pública en servicio activo, y en relación con el mismo servicio, es decir, cuando los mismos se deriven directamente de la función militar o policial que la Constitución, la ley y los reglamentos les han asignado. [...]

9.4. El objetivo del derecho penal militar es excluir comportamientos reprochables que, pese a tener relación con el servicio, denotan desviación respecto de sus objetivos o medios legitimos, que son repudiables y sancionables a la luz de la Constitución y la ley, pues en un Estado de Derecho no es tolerable el uso de medios ilegítimos para la consecución de sus fines.

De allí que la Corte, en sentencia posterior, afirmara que: "es posible que en el ejercicio de las tareas o misiones propias de la Fuerza Pública, voluntaria o culposamente, se altere radicalmente, o se incurra en excesos o defectos de acción originando una desviación de poder capaz de desvirtuar el uso legítimo de la fuerza. En efecto, son estas conductas a las que se aplica el fuero penal militar y el Código Penal Militar" (énfasis en original). La posición anterior contenida también en la Sentencia C-373 de 2011, reitera dichas líneas jurisprudenciales en materia de excepcionalidad y restricción del alcance de la competencia de la Justicia Penal Militar.

Según puede leerse en líneas anteriores, las conductas atentatorias del Derecho Internacional Humanitario no pueden ser objeto de conocimiento y juzgamiento por parte de la Justicia Penal Militar; por el contrario, para garantizar la imparcialidad y ante el evidente rompimiento del nexo causal entre la conducta y las labores propias del servicio, la tesis avalada por el máximo tribunal ha sido la de remitir estos casos a la jurisdicción ordinaria. En discordancia con esta posición, el Acto Legislativo 02 de 2012 reformatorio de los

Bogotá (1997).

8 Corte Constitucional de Colombia. Sentencia C-469 de 15 de julio de 2009. M.P. Jorge Iván Palacio Palacio. 
artículos 116, 152 y 221, establece en su artículo 3 que "las infracciones al Derecho Internacional Humanitario cometidas por miembros de la Fuerza Pública serán conocidas exclusivamente por las cortes marciales o tribunales militares o policiales, salvo los crímenes de lesa humanidad, los delitos de genocidio, desaparición forzada, tortura, ejecución extrajudicial, desplazamiento forzado y violencia sexual".

De acuerdo con los ponentes de la iniciativa, Óscar Fernando Bravo Realpe y Carlos Germán Navas Talero, entre otros, la propuesta adecúa la legislación a la situación de conflicto interno "y a la compleja realidad operacional que afronta nuestra Fuerza Pública”. Así, "[e]n el marco del conflicto armado, los delitos en los que puede incurrir un miembro de la Fuerza Pública en el ejercicio de las funciones que le ha otorgado la Constitución y la ley deben ser evaluados bajo las normas de Derecho Internacional Humanitario. En consecuencia, las conductas que puedan allegar un hecho punible deben ser de conocimiento de la justicia especializada [...]”.

Sin embargo, una perspectiva diferente ha sido expuesta con preocupación por parte de la Comisión Interamericana de Derechos Humanos (CIDH), quien estableció lo siguiente respecto a la determinación de esta reforma de aplicar exclusivamente el Derecho Internacional Humanitario para el juzgamiento de las conductas de miembros de la Fuerza Pública que podrían constituir delitos:

[E]l sistema interamericano de derechos humanos ha sostenido que en diversas circunstancias se aplican ambos cuerpos legales en forma complementaria. En consecuencia, preocupa a la CIDH la visión contenida en esta reforma constitucional, que sugiere que el derecho internacional humanitario y al [sic] derecho internacional de los derechos humanos son cuerpos legales mutuamente excluyentes 9 .

De acuerdo con lo anterior, mediante la adopción de esta reforma constitucional se estaría evadiendo la obligación del cumplimiento del Derecho Internacional de los Derechos Humanos (DIDH), el cual rige en todo tiempo, y sobre el cual poseen competencia los órganos de protección del Sistema Interamericano de Derechos Humanos en el marco de la Convención Americana sobre Derechos Humanos, encabezados por la Corte Interamericana de Derechos Humanos.

9 Comisión Interamericana de Derechos Humanos, Comunicado de Prensa No. 4 de 2013. CIDH expresa preocupación por reforma constitucional en Colombia, I (2013). 
En este orden de ideas, el Estado colombiano estaría expuesto en el futuro a ser juzgado y condenado por la violación de dicho ordenamiento, derivada de la aplicación excluyente que menciona la CIDH, y que en la práctica interna de los operadores judiciales en la Justicia Penal Militar los privaría para juzgar las conductas de su competencia bajo el prisma del DIDH.

En definitiva, la adopción de esta Norma Superior se encontraría en franca lid con la norma contenida en el artículo 3 del Código Penal Militar, cuyo control de constitucionalidad oficioso fue llevado a cabo mediante Sentencia C-469 de 2009, lo cual, a pesar de tener la virtud de dejar sin vigencia las normas de menor rango, sorprende por contradecir los motivos que acompañaron el control constitucional en mención. En esta ocasión, la Corte Constitucional estableció que de acuerdo con la objeción presidencial al artículo aludido, dado el carácter restrictivo y especial de la Jurisdicción Penal Militar, los delitos que en ningún caso podían relacionarse con el servicio debían referirse "a todas las violaciones de derechos humanos e infracciones del derecho internacional humanitario, y no solamente a los delitos de tortura, genocidio y desaparición forzada, por ser estas infracciones y violaciones contrarias a la misión constitucional y legal de la Fuerza Pública"10.

En este sentido, la nueva reforma devendría contraria al principio de la unidad normativa y a la cosa juzgada constitucional reseñada, que ha señalado la imposibilidad de someter a la competencia de la justicia castrense las infracciones al Derecho Internacional Humanitario, lo cual sin duda vicia — al menos teóricamente - los motivos del referido Acto Legislativo, sumado ello al hecho de que "graves violaciones a los derechos humanos serían conocidas por la jurisdicción militar, por ejemplo, crímenes de guerra y detenciones arbitrarias" ${ }^{11}$.

Más aun, sorprende la contradicción del Gobierno Nacional, que en el año 2009 objetó en el citado tenor, y en el año 2012 somete a la aprobación del Congreso la adopción de un proyecto de reforma en los términos que había argüido inconstitucionales. Este hecho pone en entredicho la política de Estado en esta materia y supone

10 Corte Constitucional de Colombia, Sentencia C-469 de 2009, op. cit.

11 Comisión Interamericana de Derechos Humanos (2013), op. cit. 
un incumplimiento de las obligaciones internacionales del Estado para garantizar una debida administración de justicia.

En esta línea argumental, si en principio la instauración del Estado social de derecho y la adopción de las normas de Derecho Internacional Humanitario solucionaron, al menos en el plano del ordenamiento procesal penal, las graves acusaciones de impunidad nacionales e internacionales dirigidas al fuero militar en materia penal, con esta reforma de nuevo se plantea un escenario de injusticia. Recordando el texto original de la Carta Política relacionado con el fuero, se excluían de este las conductas punibles del derecho penal ordinario, incluidas las violatorias de los derechos humanos o de lesa humanidad, hechos que bajo el régimen constitucional anterior y sus desarrollos en materia penal — especialmente durante la vigencia cuasi permanente del Estado de sitio - quedaban bajo su conocimiento, lo cual plagaba de dudas la realización de investigaciones competentes e imparciales, por no hablar de la extrema dificultad en aquella época de que se produjeran condenas. Por ello, el Acto Legislativo 02 en comento representa en alguna medida la vivificación de dicho régimen, en demérito de la problemática que vive el país y de los principios de verdad, justicia y reparación integral de las víctimas de los hechos que en adelante sean objeto de conocimiento de los tribunales militares o policiales.

De acuerdo con el Gobierno Nacional en 2006, el Código Penal Militar, fortalecía "el uso de las facultades discrecionales, sin perjuicio de los procesos de la Justicia Penal Militar, para relevar de sus cargos a oficiales, suboficiales y demás miembros de la Fuerza Pública de los que se tenga sospecha razonable de estar involucrados en casos de corrupción y casos graves de conductas indebidas" ${ }^{12}$. A pesar de que esta fuera la premisa que el gobierno se planteó, bajo la vigencia del nuevo fuero los "casos graves de conductas indebidas" serían objeto de judicialización al amparo de la Jurisdicción Castrense, so pretexto de ofrecer garantías a los implicados y proveer la especialización del juez natural.

12 Ministerio de Defensa Nacional, Cinco reformas estructurales al interior de la Fuerza Pública, (I), Bogotá (2006). 


\section{LA EXEQUIBILIDAD DE LA JUSTICIA PENAL MILITAR Y SU REFORMA}

La Corte Constitucional colombiana tradicionalmente ha avalado la exequibilidad de la jurisdicción penal militar, al argüir que tanto la Asamblea Nacional Constituyente como la propia Constitución resultante consignaron el fuero militar, recayendo por tanto en el legislador la competencia para regular, a través de las respectivas codificaciones, el diseño de su estructura y organización, de sus procedimientos de instrucción y juicio y la definición de las conductas punibles sometidas a él. En ese marco, el legislador ha establecido como principios y reglas fundamentales bajo los cuales debe desenvolverse el fuero militar los siguientes: legalidad, tipicidad, antijuridicidad, culpabilidad, favorabilidad, exclusión de analogía, igualdad ante la ley, cosa juzgada, conocimiento de la ley, juez natural, funcionalidad de la pena y de las medidas de seguridad, integración y prevalencia de las normas rectoras.

Las motivaciones expuestas condujeron al gobierno a plantear la mencionada reforma de la jurisdicción castrense, oportunidad para abrir el debate sobre temas como el de excluir del fuero militar a la policía, o a la jurisdicción militar misma de la Rama Ejecutiva - Sector Defensa, con el objeto de buscar una caracterización lo más depurada posible de dicha justicia, encauzada como garantía funcional para el más correcto servicio público de defensa y seguridad, y no ya como derecho individual o de cuerpo de los militares activos. Respecto de la reforma planteada por el ejecutivo, adicionalmente a la introducción del sistema acusatorio, en su momento informó el gobierno:

Apuntando al fortalecimiento, la independencia y la autonomía que requiere la Justicia Penal Militar, se designó a la abogada Luz Marina Gil como la primera Directora Ejecutiva civil de esta jurisdicción.

Este fue solo el primer paso de una serie de reformas estructurales que se harán y que buscan devolverle toda la credibilidad a la Justicia Penal Militar.

Acompañando los esfuerzos internos, contamos con el consejo experto de Juan Carlos Esguerra y Fernando Arboleda Ripoll en el diseño e implementación de estas reformas [...] Adicionalmente hemos convocado a un grupo de países 
amigos: Reino Unido, Estados Unidos, Suecia, Holanda y España, que aportarán su experiencia y nos acompañarán en esta revisión.

La Justicia Penal Militar no puede ni va a desaparecer. Es una institución legítima en las democracias modernas. No podemos permitir que existan dudas sobre sus fallos y decisiones, por eso una de las medidas es que pase a ser un cuerpo verdaderamente independiente de la línea de mando.

Una Justicia Penal Militar débil y cuestionada por tribunales internacionales pone en riesgo el fuero militar. El propósito es recuperar su legitimidad y credibilidad garantizando el debido proceso y la administración efectiva e independiente de justicia ${ }^{13}$.

Este afán del Sector Defensa por establecer una mejor relación y complementariedad de la Justicia Penal Militar con la justicia en general enfrentó sin embargo, un serio tropiezo. En efecto, el 14 de junio del 2006 los entonces Ministro de Defensa Nacional, Camilo Ospina Bernal, y Fiscal General de la Nación, Mario Iguarán Arana, suscribieron un acuerdo de cooperación interinstitucional para apoyar a la Justicia Penal Militar, referido únicamente al caso de muertes en operaciones militares, no haciendo relación a los demás delitos militares, militarizados o comunes, porque en cuanto a homicidios en operaciones, hay intervención legal obligatoria del Cuerpo Técnico de Investigación (CTI), no por el documento que a continuación se analiza, sino porque a partir de la vigencia del Sistema Penal Acusatorio, los militares son autoridad primer respondiente en la escena de los hechos y tienen obligaciones de iniciar la cadena de custodia de acuerdo con los parámetros y exigencias de la ley, que no es precisamente la penal militar sino la ordinaria. El acuerdo era del siguiente tenor:

El Ministerio de Defensa Nacional y la Fiscalía General de la Nación, se unen para dictar directrices frente a operaciones de las Fuerzas Militares en las que se producen hechos que revisten las características del homicidio, circunstancia que amerita la inspección técnico científica de los lugares donde hayan ocurrido los hechos.

MINISTERIO DE DEFENSA NACIONAL - FISCALÍA GENERAL DE LA NACIÓN

[...] ASUNTO: Apoyo a Justicia Penal Militar

Como es de su conocimiento, con ocasión de las operaciones propias de las Fuerzas Militares se presentan con alguna frecuencia situaciones en las que se producen hechos que revisten las características del homicidio al cual se refiere

13 Ministerio de Defensa Nacional (2006) op. cit. 
el art. 103 del Código Penal, o del homicidio en persona protegida al que alude el art. 135 ibídem; circunstancias que ameritan la inspección técnico cientifica de los lugares donde hayan ocurrido los hechos, razón por la cual, para facilitar la investigación, el Ministerio de Defensa y la Fiscalia General de la Nación expiden las siguientes directrices:

1. Que los servidores del Cuerpo Técnico de Investigación lleven a cabo las inspecciones de aquellos lugares de los hechos en donde se requiera su concurso técnico científico.

2. Que, mientras se hacen presentes en el lugar de los hechos los servidores del CTI, se realice por parte de los miembros de la Fuerza Pública su protección, atendiendo [a] la obligación legal prevista para el "Primer Respondiente".

3. Que, con el fin de facilitar el procedimiento las Fuerzas Militares deben llevar a cabo el desplazamiento oportuno de los servidores del CTI al lugar de los hechos, procurar su seguridad y el retorno a la respectiva sede.

4. Que luego de la búsqueda, fijación, recolección, embalaje y aseguramiento de las evidencias físicas y elementos materiales de prueba hallados en el lugar, asi como [de] las entrevistas de los posibles testigos, los servidores del cTI remitan los respectivos informes a las Unidades de Reacción Inmediata de la Fiscalía. 5. Que el Fiscal de la Unidad de Reacción Inmediata asumirá las diligencias a prevención, atendiendo [a] lo previsto en el artículo 29 de la Carta Política, en concordancia con el artículo 250 ibídem; del artículo 45 del Código de Procedimiento Penal y la sentencia C-358 de 1997 de la Honorable Corte Constitucional.

6. De ser evidente la existencia de los factores subjetivos y funcionales que justifican el reconocimiento del fuero instituido en el artículo 221 de la Constitución en concordancia con el artículo 250 de la Carta Fundamental, el fiscal de la justicia ordinaria decidirá con prontitud el traslado de la investigación a la Justicia Penal Militar en cuyo caso se mantendrá el apoyo técnico científico del CTI; si no se evidencian los factores enunciados continuará conociendo la Fiscalía General de la Nación, informando de esta situación a la Jurisdicción Penal Militarl ${ }^{14}$.

Mediante este acto administrativo se establecía una competencia a prevención que modificaba las reglas de competencia legales tanto de la justicia ordinaria como de la Justicia Penal Militar, competencia en razón de la cual la fiscalía iniciaba las indagaciones para luego definir si la competencia sobre esos casos le correspondía o, de lo contrario, remitir el caso a la Justicia Penal Militar.

En su momento, el cuerpo de generales en retiro juzgó tal acuerdo como una derogación en la práctica del fuero militar que afectaría a las tropas al desconocer sus derechos a una defensa y un juicio

14 Ministerio de Defensa Nacional, Mindefensa y Fiscalia firman acuerdo de cooperación, I, Boletín $\mathrm{N}^{\circ}$ 2, Bogotá (2006). 
adecuado ante su juez natural, al asignar a la fiscalía la definición de la autoridad competente para indagar y subsecuentemente juzgar respecto de los casos de estudio. Bajo esta óptica, la Defensoría Militar ${ }^{15}$ presentó demanda contra el acto administrativo de acuerdo interinstitucional, la cual fue admitida por el Consejo de Estado, quien lo suspendió provisionalmente a la luz del otrora artículo 221 y el artículo 230 de la Carta Política y según el artículo 152 del Código Contencioso Administrativo, y mediante Sentencia de fecha 15 de noviembre de $2012^{16}$, declaró la nulidad de los numerales 4,5 y 6 del acto, por encontrar una manifiesta violación de la ley fundamentada en que mientras esta radica la competencia para investigar y juzgar los delitos cometidos por los miembros de la Fuerza Pública en la Justicia Penal Militar, el acto acusado radica dicha competencia (investigativa) en las Unidades de Reacción Inmediata de la Fiscalía General de la Nación.

Por ello, desde la suspensión provisional del Acto, el juez de competencia de los soldados es la Justicia Penal Militar, pues "todas las operaciones militares deben ser conocidas por su juez natural que es la Justicia Penal Militar. Para dirimir las competencias será el Consejo Superior de la Judicatura el que falle"17.

Este suceso, además de afectar el Manual de Operaciones Militares expedido por el Comando General en diciembre del 2009, implica un deterioro del fuero militar y de las Fuerzas Militares de cara a la opinión pública nacional e internacional. Como anotan diversos medios, el hecho levanta sospechas sobre un indebido favorecimiento de esta institucionalidad y de manera más general sobre la legitimidad del Estado colombiano. Señalaba a la suspensión provisional uno de tales medios:

[...] [E]n relación con el inexplicable retardo de la justicia ordinaria (Fiscalía) en la solución de la situación jurídica de los uniformados implicados en los casos de falsos positivos, que dio lugar a la libertad de los procesados por

15 La Defensoría Militar es una corporación sin ánimo de lucro que presta el servicio de asistencia jurídica y defensa en beneficio de los integrantes activos y retirados del Ejército Nacional. Propende por el respeto de las garantías judiciales de los oficiales, suboficiales y soldados.

16 Consejo de Estado, Sala de lo Contencioso Administrativo, Sección Primera, Sentencia del quince (15) de noviembre de dos mil doce (2012). C.P.: María Elizabeth García González, Ref. Expedientes acumulados núms. 2009-00196 y 2008-00025-00.

17 L. Montes, Suspenden provisionalmente acuerdo entre la Fiscalia y Ministerio de Defensa para juzgamiento de militares, I, CM\& País, Bogotá (2010). 
vencimientos de términos, estos conservarían este privilegio jurídico, mientras el Consejo de Estado produzca su fallo y el Consejo Superior de la Judicatura defina la competencia sobre cuál debe ser el juez natural que investigue a los miembros de la Fuerza Pública por la comisión de delitos como consecuencia de las operaciones de orden público. Ahora, de rescatarse el fuero militar, no se descartan demandas indemnizatorias hacia el futuro por parte de aquellos uniformados que sienten vulnerado su derecho al debido proceso por no haber sido juzgados por el juez natural [...] de ser nulo el acuerdo, les cabría gran responsabilidad a quienes lo suscribieron, y se confirma la ausencia de asesoría jurídica en los altos funcionarios del Estado [... $]^{18}$.

Aun cuando resulta de extrema urgencia salvar este escollo, reafirmando un respeto estricto por la Constitución y el Derecho Internacional Humanitario en lo tocante al fuero y a la Justicia Penal Militar para fortalecerlos y garantizar el debido proceso y arrojar resultados operativos provechosos para la paz, para ello es imprescindible la voluntad, los recursos y los mecanismos que permitan eliminar la producción de hechos que pongan en una situación de precariedad jurídica a Colombia y a los miembros de la Fuerza Pública, y apartar con ello la imagen de un Estado que avanza improvisada e incoherentemente en la solución de cuestiones de tanta entidad como la que acá se plantea.

Esta situación de inseguridad jurídica fue el móvil de la inclusión del inciso 4 del artículo 3 del Acto Legislativo 02 de 2012. Según el texto, "[s]i en desarrollo de una acción, operación o procedimiento de la Fuerza Pública, ocurre alguna conducta que pueda ser punible y exista duda sobre la competencia de la Justicia Penal Militar, excepcionalmente podrá intervenir una comisión técnica de coordinación integrada por representantes de la jurisdicción penal militar y de la jurisdicción penal ordinaria, apoyada por sus respectivos órganos de policía judicial [...]". De acuerdo con la exposición de motivos del proyecto, las características de la comisión se traen a colación:

18 M. López, El fuero militar, I, El Tiempo, Bogotá (2010). 
i) La Comisión por ser de carácter mixto compuesta por representantes de las dos jurisdicciones tendría por objetivo constatar en cumplimiento del principio de inmediatez si un hecho puede llegar a constituir una conducta punible;

ii) El informe que emite la comisión facilita mediante su concepto técnico y especializado que se observe el marco jurídico aplicable a cada caso y se remita lo actuado a la jurisdicción competente;

iii) La Comisión debe constatar los hechos, limitándose a determinar si ha habido una conducta punible y la jurisdicción a la cual correspondería su conocimiento. La comisión no interfiere en la facultad del Consejo Superior de la Judicatura para dirimir conflictos de competencia.

La comisión es un espacio permanente de coordinación, de carácter mixto, compuesta por representantes de la Jurisdicción Ordinaria y Penal Militar, que apoyados en la policía judicial de ambas jurisdicciones tiene como cometido primordial conceptuar de manera técnica y especializada si en un caso concreto se ha cometido o no un delito y en este último evento enviar su concepto a la jurisdicción que debe iniciar esa investigación.

La comisión, verificados los hechos, procederá de inmediato a enviar las actuaciones a la Jurisdicción Ordinaria o a la Penal Militar, según corresponda. [...] Se trata de una comisión de coordinación y no de un tribunal de carácter jurisdiccional que decide competencias [...] se limita a presentar un concepto técnico y especializado basado en las constataciones probatorias ${ }^{19}$.

De acuerdo con tales explicaciones, "la aplicación de las reglas de competencia constitucionales y legales son las llamadas a establecer primariamente la competencia. La comisión mixta opera excepcionalmente con carácter técnico cuando estas reglas no ofrezcan suficiente claridad". En todo caso, establece la exposición de motivos transcrita, que el Consejo Superior de la Judicatura siempre tendrá la facultad de dirimir los conflictos de competencia.

Lo anterior, aunado a la incoherencia de la reforma en lo tocante a las competencias de ambas jurisdicciones, deviene en una situación de derecho más compleja de la que se propone remediar, en tanto la competencia permanente del Consejo Superior de la Judicatura para dirimir conflictos de jurisdicción entre la Justicia Penal Militar y la Justicia Ordinaria sería la misma otorgada al nuevo Tribunal de Garantías Penales creado por la reforma al artículo 116 Superior $^{20}$, mientras que la Comisión mixta creada

19 Congreso de la República, Gaceta del Congreso No. 111, Informe de ponencia para primer debate al Proyecto de Acto Legislativo Número 192 de 2012 Cámara, Por el cual se reforman los artículos 116, 152 y 221 de la Constitución Política de Colombia, Imprenta Nacional, Bogotá (2012).

20 De acuerdo con el texto, la reforma da atribución al nuevo Tribunal de manera permanente para "dirimir los conflictos de competencia que ocurran entre la Jurisdicción Ordinaria y la 
por el reformado artículo 221 tendría la función de determinar si ha habido una conducta punible y la jurisdicción competente para resolver los casos en que la aplicación de las reglas constitucionales y legales no permita establecer la competencia. Aunque la exposición de motivos se esfuerza en afirmar que esta decisión no es jurisdiccional, pues la Comisión actuaría de forma excepcional basada en constataciones probatorias, el texto no deja de ofrecer serios errores de técnica legislativa que evidencian la improvisación sobre estos temas.

Más aún, dado que la reforma somete a reglamentación mediante ley estatutaria el funcionamiento de las nuevas figuras creadas, como lo ha considerado la $\mathrm{CIDH}$, el Acto Legislativo "contiene disposiciones ambiguas que están supeditadas a una ley estatutaria posterior, y por lo tanto genera incertidumbre jurídica"21.

Quizá uno de los aspectos más graves de la reforma en estudio es el hecho de que esta "invierte la regla actual reconocida en la jurisprudencia reiterada de los órganos del sistema interamericano, de que los casos sean resueltos en la jurisdicción ordinaria, siendo excepcional la transferencia a la Justicia Penal Militar" debido a que "la reforma establece que casos relacionados con el servicio serían conocidos por el fuero militar y que, en caso de duda, excepcionalmente, una Comisión mixta integrada por representantes de la jurisdicción militar y ordinaria intervendrá para determinar la competencia”22.

\section{FUERO MILITAR Y LIBERTADES FUNDAMENTALES}

Además de la impropiedad de la reforma al fuero militar, esta investigación también se concentra en disertar brevemente sobre el fuero militar y su íntima relación con el ejercicio de las libertades fundamentales, siendo la libertad para el desarrollo de la personalidad (art. 16, CP) una de las más limitadas bajo el régimen de vida militar. Se trata de la libertad interna o psicológica, que es el poder o independencia del titular del derecho de elegir o diseñar un curso de acción u omisión, por sí mismo, sin injerencia extraña

Jurisdicción Penal Militar" (Numeral 3).

21 Comisión Interamericana de Derechos Humanos, 2013, Op. Cit.

22 Ibíd. 
no querida, para el caso de estudio sujeta a jerarquía, órdenes y reglas militares respecto de quien se encuentra bajo el fuero militar y que limita, por ejemplo a los reclutas, escoger libremente opciones de educación, profesión u oficio, o inclinaciones políticas. También denominada libertad moral o independencia para llevar a cabo todo aquello que no está jurídicamente prohibido, que en el supuesto de quienes están bajo la égida militar puede conducir incluso a afrontar situaciones extremas que rompen el fundamento límite del derecho a la vida, cual es el de respetar la ajena, imponiéndose al militar el deber, llegado el caso, de matar o lesionar a sus semejantes en ejercicio del monopolio legítimo de la violencia por parte del Estado.

En principio estos tipos penales imponen a quienes se encuentran sujetos al fuero militar el deber de la valentía. En ese sentido, ha dicho la Corte Constitucional que el acto de valor, para un militar, es apenas debido, no excepcional ${ }^{23}$. Según la corporación, la exigencia de valor encuentra fundamento en lo siguiente:

[L] a formación del militar (y hay que agregar entre nosotros al policía, aunque su asimilación no es del todo adecuada) es un adiestramiento permanente dirigido a un objetivo especifico: saber afrontar las situaciones de peligro. Ahora bien, es de suponer que quien se ejercita en una actividad, desarrolla destrezas que se incorporan al repertorio de sus acciones y reacciones cotidianas, que vistas desde afuera pueden parecer excepcionales y extraordinarias pero que para él deben aparecer como normales. Por tanto, en ese campo especifico la exigencia que para otro podría ser desmesurada, para él es razonable: afrontar un combate, no huir, no hacer manifestaciones de pánico. La valentía, entonces, asi entendida, y vinculada al honor militar, se revela como una destreza exigible de quien se ha preparado para adquirirla, y el no poseerla sería tan vergonzoso (;deshonroso!) como lo sería para quien ha recibido adecuado entrenamiento en el quirófano, no ser capaz de realizar una operación de cirugía corriente. No es descartable, en ninguno de los dos casos, que circunstancias particulares, especificas, personales o externas, frustren la observancia de la conducta exigible, pero se trata entonces de casos "anormales" que merecen una consideración especial que también el ordenamiento normativo debe tomar en cuenta.

Asi pues, el acto de valor (como todos los enunciados en las normas demandadas) que para un ciudadano común podría ser heroico, y cuya omisión no sería

23 Corte Constitucional de Colombia, Sentencia C-563 de 30 de noviembre de 1995, M.P.: Carlos Gaviria Díaz. 
vergonzosa, para un militar sería apenas debido, y su incumplimiento motivo de baldón (considerando 3).

Ahora bien, como señala la Corte, este deber no es absoluto, pues "si entran en tensión el valor exigido al miembro de la Fuerza Pública y el núcleo esencial de un derecho fundamental como la vida o la integridad personal cuando exista muy alta probabilidad de que en determinadas circunstancias estas corran serio riesgo de pérdida o afectación grave y no es exigible otra conducta distinta, ha de primar el derecho fundamental" 24 .

Estos criterios, conforme a las circunstancias en cada caso concreto, deberán ser apreciados por el juez de conocimiento a fin de definir si cabe un juicio de reproche por la cobardía de quien, sujeto al fuero militar, ha realizado una de estas conductas, así como para determinar el grado de responsabilidad del procesado.

En este tema de la protección del honor militar es incontestable que el decoro, el público ejemplo o comportamiento decente por parte del militar es uno de los deberes derivados del servicio, como valor propio de la institución castrense en cuanto bien jurídico tutelado simultáneamente con otros, como la integridad física o la propiedad, en tipos penales de alcance pluriofensivo.

\section{PERSPECTIVA SOCIOLÓGICA DEL FUERO MILITAR EN COLOMBIA}

En la parte final de este artículo y en el marco de la investigación denominada "Estructura y atribuciones de las Fuerzas Militares colombianas. Constitución, problemas socio-jurídicos y teoría política" ${ }^{25}$, finalmente, y a manera de contraste entre las posiciones dogmáticas y técnicas sobre el fuero militar y la concepción de quienes viven investidos con este, a continuación se expone una noción a nivel institucional e individual de los miembros de las Fuerzas Militares, respecto a la siguiente cuestión: ¿Cree que el fuero mili-

24 Corte Constitucional de Colombia, Sentencia C-228 de 18 de marzo de 2003, M.P.: Alfredo Beltrán Sierra.

25 Resultados de investigación de tesis doctoral denominada "Estructura y atribuciones de las Fuerzas Militares colombianas. Constitución, problemas socio-jurídicos y teoría política" llevada a cabo entre los años 2008-2012. 


\section{Tabla 1. ¿Cree que el fuero militar es garantía funcional o condición de impunidad?}

\begin{tabular}{|l|c|c|c|c|}
\hline & Frecuencia & Porcentaje & $\begin{array}{c}\text { Porcentaje } \\
\text { válido }\end{array}$ & $\begin{array}{c}\text { Porcentaje } \\
\text { acumulado }\end{array}$ \\
\hline Garantía funcional & 143 & 81,7 & 81,7 & 81,7 \\
\hline No es garantía funcional & 11 & 6,3 & 6,3 & 88,0 \\
\hline Opina con comentario & 8 & 4,6 & 4,6 & 92,6 \\
\hline Fuero militar no existe & 6 & 3,4 & 3,4 & 96,0 \\
\hline $\begin{array}{l}\text { No responde, no opina, } \\
\text { no sabe }\end{array}$ & 4 & 2,3 & 2,3 & 98,3 \\
\hline Condición de impunidad & 3 & 1,7 & 1,7 & 100,0 \\
\hline Total & 175 & 100,0 & 100,0 & \\
\hline
\end{tabular}

tar es una garantía funcional o una condición de impunidad? Las respuestas pueden sintetizarse asi ${ }^{26}$ :

Según los resultados expuestos, el $81,7 \%$ de los entrevistados considera que el fuero militar es una garantía funcional; el 6,3\% considera que no lo es, y apenas el 1,7\% lo considera una condición de impunidad. Estas son algunas de las razones expuestas:

Se puede prestar para los dos casos, mal manejado, lastimosamente.

Ese fuero es teórico y en la práctica no existe.

Debería ser una garantía pero debido a múltiples factores se ha desprestigiado y por eso casi ha desaparecido.

El fuero militar es una condición necesaria para que podamos desempeñar nuestra función.

Los funcionarios públicos y abogados entrevistados consideran que el fuero es una garantía funcional de origen constitucional; las situaciones de impunidad se originan no en el fuero como tal, sino en la gestión judicial de sus administradores y en la falta de apoyo y colaboración de los usuarios del servicio.

26 La encuesta se aplicó en 2009 a 141 integrantes del Curso de Estado Mayor de la Escuela Superior de Guerra, miembros de las Fuerzas Militares de diferentes procedencias, en los rangos de mayor y capitán capacitados para asumir los cargos de comandantes de las unidades militares de las tres fuerzas, con responsabilidad operacional en todo el territorio nacional. En la actualidad son comandantes de las unidades operativas en las unidades estratégicas de todo el país. Un segundo grupo correspondió a 32 coroneles que adelantaron el Curso de Altos Estudios Militares para ser Generales y Almirantes de la República. Las mismas preguntas fueron realizadas a 30 funcionarios públicos y abogados del área para ampliar la información y comparar sus puntos de vista con el de los militares entrevistados. 


\section{Figura 1. Relación entre respuestas}

Fuero militar: ¿garantía funcional o condición de impunidad?

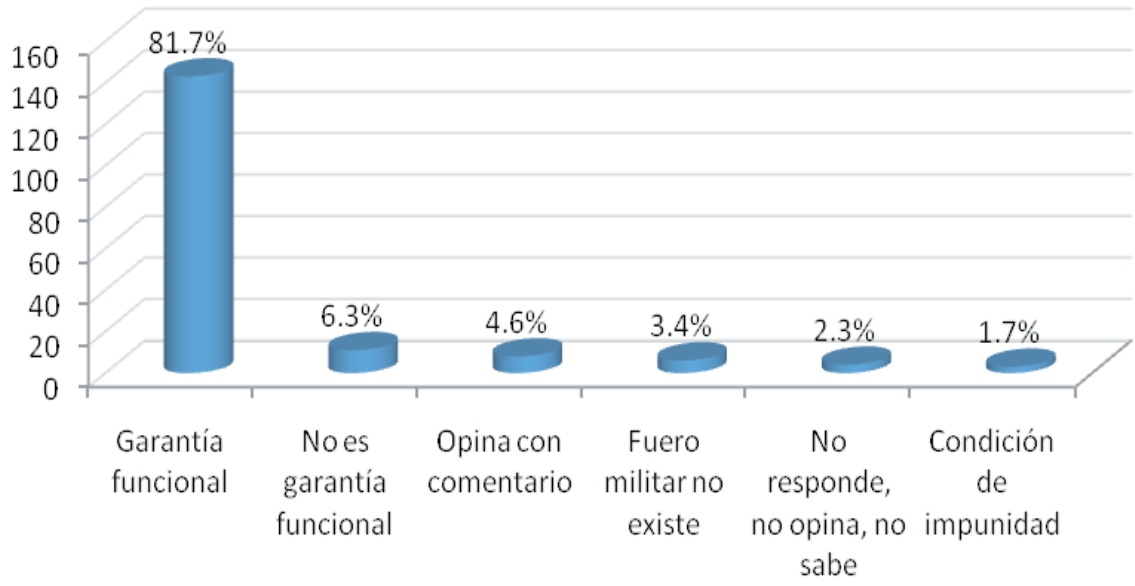

Otra de las preguntas relacionadas fue la siguiente: ¿Qué políticas estatales deben adoptarse para rescatar la credibilidad de la Justicia Penal Militar?

\section{Figura 2. Políticas para legitimar a la Justicia Penal Militar}

\section{¿Qué políticas estatales deben adoptarse para rescatar la credibilidad de la justicia penal militar?}

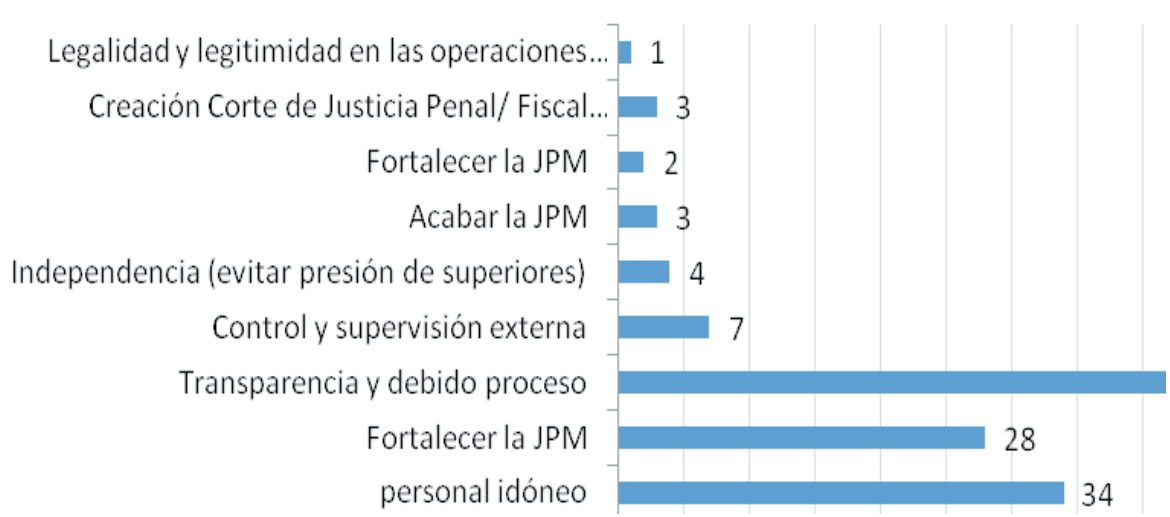


Dentro de las principales vías de solución propuestas por los entrevistados, se encuentra dejar la Justicia Penal Militar en manos de personal idóneo para fortalecerla. La respuesta más frecuente subraya la necesidad de transparencia y del debido proceso, mientras que llama la atención la propuesta de crear instancias superiores, como una Corte de Justicia Penal Militar y un fiscal especializado.

Por su parte, los funcionarios públicos y abogados resaltan la importancia de fortalecer el cuerpo de Justicia Penal Militar, que garantice la independencia de los jueces desde su designación, incluyendo su régimen salarial y de carrera; mayores exigencias de calidad personal y profesional a los funcionarios que la integran; mayores apoyos logísticos y técnicos para realizar investigaciones serias y oportunas. 


\section{CONCLUSIONES}

El fuero penal militar es el derecho de los miembros de la Fuerza Pública a ser juzgados por un juez especializado diferente al que ordinariamente tiene la competencia y cuya finalidad es que dentro del marco de la Constitución (artículo 221), estén cubiertos en sus actividades del servicio por un marco jurídico especial; por ende, esta justicia constituye una excepción constitucional a la regla del juez natural. Para el funcionamiento de esta justicia especializada se crearon los tribunales militares, que en ningún caso podrán juzgar a los civiles.

El fuero penal militar es garantía funcional y debe mantenerse, porque este no corresponde a un privilegio injustificado para los miembros de la Fuerza Pública por los delitos que comentan con ocasión del servicio que cumplen, para generar impunidad. Debe tenerse en cuenta que su comisión se da en condiciones materiales y jurídicas diferentes de las personas que delinquen y sobre las que recae la acción punitiva del Estado ${ }^{27}$.

Frente al alcance del derecho al fuero militar, la Corte Constitucional ha expresado y ratificado que no es posible extraer del texto constitucional una disposición que imponga que la Justicia Militar deba contar con un procedimiento y unas normas adjetivas diferentes a las del resto de los funcionarios públicos ${ }^{28}$.

En consecuencia, el derecho al fuero, según la Corte, implica solamente que la Justicia Militar debe contar con una normativa sustancial especial, compatible con las conductas delictivas e ilegales especiales que sus miembros pueden cometer en razón de sus funciones ${ }^{29}$.

27 Corte Constitucional, Sala Plena de Constitucionalidad, Sentencia C-399 del 7 de noviembre de 1995, M.P.: Alejandro Martínez Caballero.

28 Ver sentencias C-310 de 1997 y C-620 de 1998 donde la Corte Constitucional conceptúa acerca de la posibilidad de unificar el proceso disciplinario de todos los funcionarios públicos.

29 A este respecto, en la Sentencia C-620 de 1998 la Corte Constitucional estimó: "[...] las diferencias existentes entre los estatutos disciplinarios de las Fuerzas Militares y la Policía Nacional $y$ los aplicables a los demás funcionarios públicos, radican, exclusivamente, en los aspectos de orden sustancial —las faltas en que pueden incurrir y las sanciones que le son aplicables - y no en el procedimiento que debe surtirse para imponer la sanción, pues alli es perfectamente posible que el legislador fije una regulación común sin que por eso se entiendan afectados los regímenes especiales y, en consecuencia, las disposiciones constitucionales que los consagran. Incluso, haciendo mención a los principios rectores que gobiernan el debido proceso, estimó la Corte que los mismos deben identificarse en todos los sistemas disciplinarios por cuanto su objetivo fundamental es el de garantizar a los servidores públicos, sin distingo ninguno, el respeto de sus 
Otro punto relevante, es que los regímenes especiales solo pueden comprender las regulaciones íntimamente vinculadas con su objeto específico, en virtud de lo cual es la conexión con el servicio lo que marca la competencia de la instancia judicial y no simplemente la condición de miembro de la Fuerza Pública. En el caso de violaciones a los derechos humanos o de conductas delictivas que carezcan de relación "directa" con el servicio, tales personas quedarán sometidas a la normatividad ordinaria, penal o disciplinaria según sea el caso. Es precisamente en este punto donde se llega a la conclusión de que la reforma no era necesaria como garantía funcional, pues desde la Constitución de 1991 se consagró un fuero penal militar ajustado a derecho, y con el Acto Legislativo 02 de 2012 se hacen ilusorias las garantías para las víctimas.

El fuero penal militar es una investidura especial que responde a las diferencias entre los deberes y responsabilidades que tienen los ciudadanos y los que están llamados a asumir los miembros de la Fuerza Pública, "pues a estos últimos la Constitución les asigna una función especial, exclusiva y excluyente: el monopolio del ejercicio coactivo del Estado, que implica el sometimiento a unas reglas especiales propias de la actividad militar"30. Por ello, la finalidad esencial de este fuero "es que, dentro de los marcos de la Constitución, los miembros de la Fuerza Pública estén cubiertos en sus actividades de servicio por un régimen jurídico penal especial, tanto sustantivo como procedimental, que sea acorde con la especificidad de la organización y funcionamiento de la Fuerza Pública"'31.

Del mismo modo, la incoherencia de la reforma en estudio que otorga facultades permanentes para la dimisión de conflictos de competencia entre la Justicia Penal Militar y la Justicia Ordinaria a dos órganos - Consejo Superior de la Judicatura y Tribunal de Garantías Penales - y a su vez da atribución a una Comisión cuyos integrantes serían de ambas jurisdicciones antedichas para establecer la competencia en los casos donde no sea clara esta, deja entrever lo innecesario de la reforma propuesta.

derechos constitucionales durante el trámite del proceso que se surte en su contra (art. 29 C.P.)".

30 Corte Constitucional de Colombia, Sentencia C-141 de 1995, op. cit.

31 Corte Constitucional de Colombia, Sentencia C-928 de 7 de noviembre de 2007. M.P.: Humberto Antonio Sierra Porto. 
Las Fuerzas Militares deben cumplir con los valores y fines constitucionales, en especial con el respeto y garantía de los derechos humanos y con el principio democrático. Y a partir de allí, hacer los esfuerzos para vencer a los grupos violentos, ojalá por medios políticos antes que por medios violentos, porque es obligatorio, para tratar el tema del fuero militar, reconocer la problemática interna que vive el país. 


\section{BIBLIOGRAFÍA}

Alfredo Vásquez Carrizosa, Gaceta Constitucional Número 10. Proyecto de acto Reformatorio de la Constitución Política de Colombia No. 12. Reforma Constitucional sobre los Derechos Humanos, I, 1, Asamblea Nacional Constituyente, Bogotá (1991).

Comisión Interamericana de Derechos Humanos, Comunicado de Prensa No. 4 de 2013. CIDH expresa preocupación por reforma constitucional en Colombia, I (2013).

Congreso de la República, Acto Legislativo $\mathrm{N}^{\circ} 02$. Por el cual se reforman los artículos 116, 152 y 221 de la Constitución Política de Colombia. Diario Oficial No. 48657 (2012).

Congreso de la República, Gaceta del Congreso No. 111, Informe de ponencia para primer debate al Proyecto de Acto Legislativo Número 192 de 2012 Cámara, Por el cual se reforman los artículos 116, 152 y 221 de la Constitución Política de Colombia, Imprenta Nacional, Bogotá (2012).

Congreso de la República, Gaceta del Congreso No. 343, Texto propuesto para conciliación en primera vuelta al Proyecto de Acto Legislativo Número 16 de 2012 Senado, 192 de 2012 Cámara, Por el cual se reforman los artículos 116, 152 y 221 de la Constitución Política de Colombia, Imprenta Nacional, Bogotá (2012).

Consejo de Estado, Sala de lo Contencioso Administrativo, Sección Primera, Auto de fecha 14 de diciembre de 2009 admisorio de la demanda de constitucionalidad contra el acto administrativo denominado "Apoyo a la Justicia Penal Militar". C.P.: María Claudia Rojas Lasso, Exp. Radicado No. 11001032400020090019600.

Consejo de Estado, Sala de lo Contencioso Administrativo, Sección Primera, Sentencia del quince (15) de noviembre de dos mil doce (2012). C.P.: María Elizabeth García González, Ref. Expedientes acumulados núms. 2009-00196 y 2008-00025-00.

Corte Constitucional de Colombia, Sentencia C-141 de 29 de marzo de 1995. M.P.: Antonio Barrera Carbonell.

Corte Constitucional de Colombia, Sentencia C-228 de 18 de marzo de 2003. M.P.: Alfredo Beltrán Sierra.

Corte Constitucional de Colombia, Sentencia C-310 de 25 de junio de 1997. M.P.: Carlos Gaviria Díaz.

Corte Constitucional de Colombia, Sentencia C-358 de 5 de agosto de 1997. M.P.: Carlos Gaviria Díaz.

Corte Constitucional, Sala Plena de Constitucionalidad, Sentencia C-399 del 7 de noviembre de 1995. M.P.: Alejandro Martínez Caballero.

Corte Constitucional de Colombia, Sentencia C-469 de 15 de julio de 2009. M.P.: Jorge Iván Palacio Palacio.

Corte Constitucional de Colombia, Sentencia C-563 de 30 de noviembre de 1995. M.P.: Carlos Gaviria Díaz.

Corte Constitucional de Colombia, Sentencia C-620 de 4 de noviembre de 1998. M.P.: Vladimiro Naranjo Mesa. 
Corte Constitucional de Colombia, Sentencia C-928 de 7 de noviembre de 2007. M.P.: Humberto Antonio Sierra Porto.

Fundación Ideas para la Paz, Las condiciones de la tortura, I, Siguiendo el conflicto: hechos y análisis de la semana, 1 (2006).

L. Montes, Suspenden provisionalmente acuerdo entre la Fiscalía y Ministerio de Defensa para juzgamiento de militares, I, CM\& País, Bogotá (2010).

L. Pérez Casas, Colombia, la impunidad al orden del día. La Justicia negando la Justicia, (I), Jornadas organizadas por Jueces para la Democracia, Ávila - Colectivo de Abogados José Alvear Restrepo, Bogotá (1997).

M. López, El fuero militar, I, El Tiempo, Bogotá (21 de enero de 2010).

Ministerio de Defensa Nacional, Cinco reformas estructurales al interior de la Fuerza Pública, I, Bogotá (2006).

Ministerio de Defensa Nacional, Directiva Permanente $N^{\circ} 19$. Reiteración obligaciones para autoridades encargadas de hacer cumplir la ley y evitar homicidios en persona protegida, I, Bogotá (1997).

Ministerio de Defensa Nacional, Mindefensa y Fiscalía firman acuerdo de cooperación, I, Boletín N², Bogotá (2006). 
